Check for updates

Shine Cancer Support

Cite this as: BMJ 2022;376:0397 http://dx.doi.org/10.1136/bmi.0397 Published: 15 February 2022

\section{Covid-19: For the clinically extremely vulnerable, life hasn't returned to normal}

\author{
Ceinwen Giles co-CEO
}

I spent last week hoping I had covid.

What started off as a scratchy throat developed into a stuffy nose, slight cough, and a general feeling of being unwell. “Could this be it?,” I wondered to myself as I did multiple lateral flow tests.

Odd though it may be, my thinking was that although I was ill, I wasn't that ill. If this was covid, maybe I'd be okay. Of all the stresses over the past two years, the uncertainty about what covid may or may not do to me is one of the hardest to live with (note: it wasn't covid). I have an immune deficiency which means I don't effectively create the B cells which play an integral role in fighting off infection. It also means I don't produce as good a response to vaccines as the average person. This means that despite dutifully having my four covid vaccinations, since March 2020 I've lived a weird kind of half-life, where I still remain vulnerable to a virus that others are increasingly forgetting about.

At first, I shielded religiously. I saw no one, but my husband and daughter, and I didn't dare go inside anywhere other than my home. The government sent me-and 1.5 million people like me-somewhat terrifying letters and texts warning us that we were at extreme risk. But they also put into place useful programmes, such as the delivery of food parcels and medicines, and enabled shielders to claim statutory sick pay if they were unable to go to their usual place of work.

We all knew that this couldn't go on forever-and who would want it to? But, since the start of the "great reopening" in the middle of 2021, it seems the government has conveniently forgotten about the 1.5 million vulnerable people they were so eager to protect back in early 2020. The shielding programme was paused in April 2021, then quietly dropped a few months later. The Department of Health and Social Care said that the clinically extremely vulnerable should follow the same advice as the rest of the population, but with some additional suggested precautions such as avoiding "enclosed crowded spaces.” And last week, Boris Johnson, UK prime minister, told us that the pandemic is essentially over-all restrictions will end very soon, including the need to self-isolate.

Except for the vulnerable, the pandemic isn't over. Life hasn't returned to normal, and what has been a difficult two years now appears to stretch ever further into the future with no real prospect of "normal" life anytime soon. The government's message that "vaccinations are the best way to protect yourself" is hollow advice for people like us.

Clinically vulnerable people now have no legal right to work from home, or to request different roles if their job puts them at increased risk, or to claim statutory sick pay. Those of us with children face a daily game of covid roulette, sending our children into schools where the virus is rife and public health measures are often absent. Masks may still be mandatory on some forms of public transport, but compliance is waning and they soon won't be required. Anti-vaccine rhetoric has reached fever pitch.

The sense of despair I feel as the world moves forward and I am slowly left behind is crushing. What is the point? I wonder late at night as government advice to continue to avoid "enclosed crowded spaces" means using public transport less, avoiding visits to offices and work events, and being unable to spontaneously participate in the taken-for-granted everyday pleasures of shopping, going to the cinema, or a restaurant.

The clinically vulnerable obviously can't take to the streets in protest-surely one reason we don't feature on television debates and in truck convoys is because of our aversion to crowds. I know I am not alone in my despair. Many friends and colleagues who live with cancer or other conditions have contacted me over the last year, asking how I keep my spirits up. The answer is that I haven't. Friends ask whether I think they're being paranoid if they avoid large gatherings-I don't. But other than virtual hugs and supportive words between us, we face being left out of the best parts of life by a government and some parts of society who think we all just need to "get on with it.”

It doesn't need to be like this. Somewhere between the deeply polarised positions of "lockdown" and "freedom" is a space where we could support those who have so much to contribute, but are being shut out. The government could appoint someone within the Department of Health and Social Care with responsibility for the vulnerable and

immuno-compromised, ensuring all policies have an equality impact assessment so they are not disadvantaged. It could ensure that free testing continues, that those with covid infections isolate, and that access to antiviral therapies is made much more easily available. It could ensure that masks continue to be worn on public transport and shops. None of these precautions would hamper the public's "freedom," but would make life more manageable, and less stressful, for those most at risk. There is also much more discussion to be had about pre-exposure therapies, which have been given emergency use authorisation for high risk individuals in the US, but seem hardly to be talked about in the UK, despite an emerging evidence base. ${ }^{1}$ 
When I think back to the early days of the pandemic and the fear and sadness I felt as we locked down, as friends and colleagues fell seriously ill and died, and as we clapped for the NHS, I was grateful for the scientists, doctors, key workers, vaccines, and research. We felt like a country connected, a nation united. Now, two years later, after all the pain, work, and sacrifice, it seems to me that maybe we are not all in this together after all.

Competing interests: Please see bmi.com for full declaration of interests

Provenance and peer review: commissioned, not peer reviewed

1 Levin MJ, Ustianowski A, De Wit S, etal. LB5. PROVENT: Phase 3 Study of Efficacy and Safety of AZD7442 (Tixagevimab/Cilgavimab) for Pre-exposure Prophylaxis of COVID-19 in Adults. Open Forum Infect Dis 2021;8(Suppl 1):S810. doi: 10.1093/ofid/ofab466.1646. 